\title{
DIGITAL EDUCATION USING FREE AND OPEN SOURCE TOOLS TO ENHANCE COLLABORATIVE LEARNING
}

\author{
Qais Ali Mohammed ${ }^{1}$, Vikas Rao Naidu ${ }^{2 \star}$, Raza Hasan ${ }^{3}$, \\ Muhammad Mustafa ${ }^{4}$, Karan Ajit Jesrani ${ }^{5}$ \\ ${ }^{1}$ Mr., Middle East College, OMAN,13f10559@mec.edu.om \\ ${ }^{2}$ Mr., Middle East College, OMAN, vikas@mec.edu.om \\ ${ }^{3} \mathrm{Mr}$., Middle East College, OMAN, raza@mec.edu.om \\ ${ }^{4}$ Mr., Middle East College, OMAN, 11s7131@mec.edu.om \\ ${ }^{5}$ Mr., Middle East College, OMAN, kjesrani@mec.edu.om \\ ${ }^{*}$ Corresponding author
}

\begin{abstract}
The use of Open source tools has been increasing over the years in various fields including the teaching and learning field. It is a better way of utilizing tools with a lower cost than the market tools that are available as well as the same tool can be customized to fit an institute (or a specialization). By integrating the collaborative methods and techniques with the open source tools that were customized, the students and teachers would be able to achieve collaborative teaching and learning more effectively as well as the teacher would have a better way of delivering the learning outcomes by the help of the tools. Moreover, the tools would assist in clearing the distractions that the students may have during the class by giving them tasks through tools and keep them engaged and away from what can distract the students during a lecture. Furthermore, open source tools can provide a rather fun and unique experience for the students to interact with each other as well as with the teacher to meet the objectives of the modules as well as build a sense of teamwork between the students which can help the student not only achieve the learning outcomes but also assist in their careers after they finish with their studies.

The open source tools will be divided into categories through which the teachers would be able to choose from depending on the learning outcomes of their lessons. A framework is suggested by the authors to use the open source tools in the most effective way.
\end{abstract}

Keywords: FOSS Tools in Education, Education Technology, E-learning, Collaborative Learning environment, Innovation in Teaching and Learning

\section{INTRODUCTION}

The technology has taken the education system to a new horizon and everyday with the advancement of latest e-learning tools, challenges are increasing in order to devise an effective mechanism. Several researches has been conducted in this field and results had shown a very drastic change just in last two decades. Different teaching and learning environment has different needs related to transformation of knowledge from faculty to the students. These days every teacher or faculty, especially in higher education sector, is digitally literate and able to use technology classroom teaching, apart from various types of assessments. But when it comes to some specific type of learning environment, such as collaborative 
learning environment, which involves more than one students working in group, the challenges increases.

There are several tools to assist such kind of teaching and learning environment. This research paper highlights the need of a new framework, since existing systems needs update with the period of time and with change in the syllabus, as technology advances.

\section{RELATED WORK}

Education to an extent is a creative act, an artistic enterprise to transferring the knowledge to students. It's a role of a teacher to disseminate knowledge through best methods in the classroom. Responsibility of teacher is to identify the needs of the student's and their problems faced in acquiring the knowledge. Simulators are used to teach computer hardware for the better understanding of the students, this gives the inside working of the hardware so students can visualize the actual working (Hasan \& Mahmood, 2012) (Siddiqui, Hasan, Mahmood, \& Khan, 2012) (Kazmi, Hayat, Hasan, \& Dattana, 2017). By using blended learning used to increase the student learning experience where both practical and theoretical concept has to be infused (Hasan, Ali, \& Hayat, 2015). To improve discovery learning procedure to visualize and explore example in short span of time. Integrating technology and multimedia tools are used to enhance student's experience of learning such as GeoGebra for mathematical and statistical analysis (GebreYohannes, Bhatti, \& Hasan, 2016) (Bhatti, Hasan, Farsi, \& Kazmi, 2017). Few attempted activity based learning to enhance student engagement and learning experience where the teacher observed the impact of teaching and learning impacts (Hayat, Hasan, Ali, \& Kaleem, 2017). Learning environment is created to foster best learning practices and engaging students to fullest (Bhatia \& Naidu, 2017) (Naidu, Singh, Hasan, \& Hadrami, 2017). Interactivity tools are implemented to increase the understanding of fundamental concepts (Raweehi, Ansari, Udupi, \& Naidu, 2017) (Farsi, Udupi, \& Naidu, 2017). Open source tool plays a vital role in education where teachers can swiftly adopt and enhance the teaching and learning process (Naidu, Balushi, \& Bhatia, 2017) either through game or technology assisted learning (Naidu, Singh, Harrasi, \& Balushi, 2017).

It is evident from the literature review, technology and tools are important to transfer the knowledge. It is also important that whatever the learning style is adopted not only the teacher involvement with students are necessary for disseminate the knowledge but also among the peers as a collaborative learning environment for an enhanced learning experience. From the related study it is being found that there is a need to bridge the appropriate tools and the selection method of learning styles. This can help in longer run as it will incorporate in all types of learning levels.

\section{ANALYSIS FOR THE PROPOSED SYSTEM}

There are many tools available at present and if we re-shape their usage by ordering them properly we can device a very effective framework. Although the success of this framework could be measured only after getting the results of cohort, for which it is going to be deployed. Also the effectiveness could also be seen by means of collecting feedback from the end users such as teachers and the students.

Before planning the design of proposed system, a survey was conducted among 30 students from Middle East College, on of the well-known private higher education institution in Oman, as well as 20 students from other colleges across the country to assess the use of e-learning tools as well as if collaborative teaching and learning methods are being implemented in educational institutes.

Question 1 (analyzed by Fig. 3.1): Have you ever been a part of a collaborative learning session?

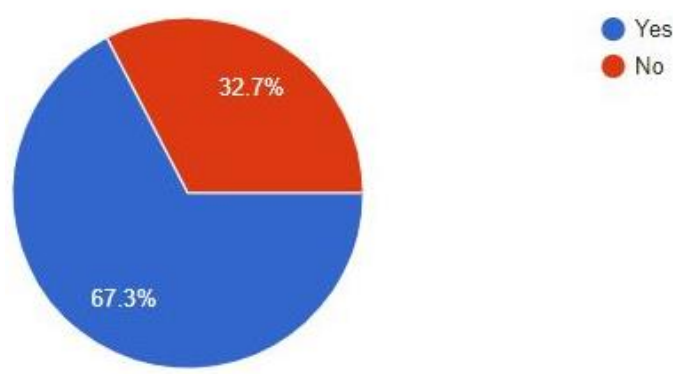

Fig 3.1: Analysis Question 1

Question 2 (analyzed by Fig. 3.2): Do you think shifting the classroom to an e-learning environment will make the students achieve targets better? 


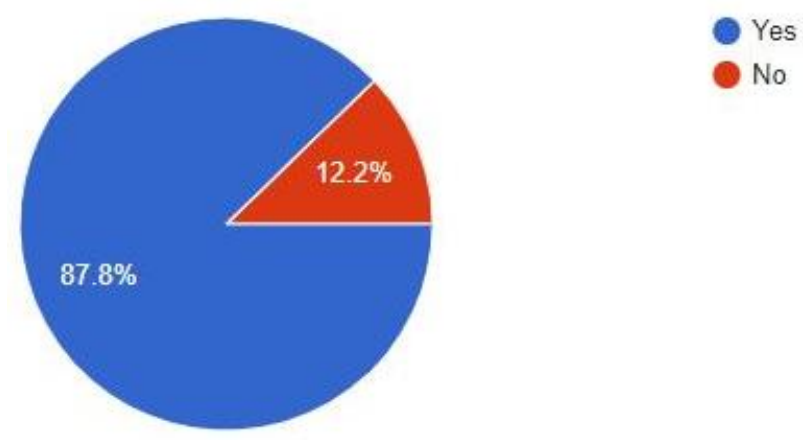

Fig 3.2: Analysis Question 2

The aim of this question was to check whether the students may accept shifting the class from the standard paper handouts and board explanation to an e-learning environment with the usage of open source tools and virtual boards. On this question, 49 out of the 50 respondents responded as well. 43 out of 49 answered Yes while 6 answered No. which means that most of the students do accept the change and believe that they would achieve better if the e-learning environment was applied to their classrooms.

Question 3 (analyzed by Fig. 3.3): Working in groups and collaborating with other students enhances the outcome of students.

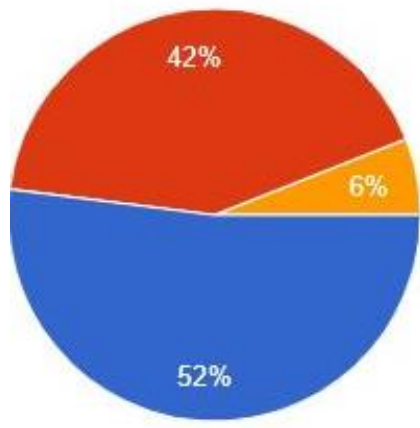

Fig 3.3: Analysis Question 3

This question was asked to the students to ensure that working in groups or collaborating with other students enhances their own outcome. 50 out of 50 respondents answered this question in which 26 responded with Agree, 21 responded with Neutral and 3 responded with Disagree. The responses varied mostly between Agree and Neutral which means that half of the students do agree with the statement and think that working in collaborative learning environment is infact increasing their outcomes, while the other $42 \%$ are neutral which means it doesn't affect their outcomes, and finally 3 respondents disagree with the statement which means that they might have had a bad experience with a group or do not prefer to be in a group while in class.

Question 4 (analyzed by Fig. 3.4): What are the e-learning tools that are used in your institute?

This question addresses the e-learning tools that are currently being used in the education institutes of the respondents. 50 out of 50 answered this question. 37 of the respondents chose Moodle while 7 chose Google classroom and Task Board, 3 chose Peergrade, 1 chose Litmos LMS and BlackBoard, 3 respondents added Kahoot as an answer. 


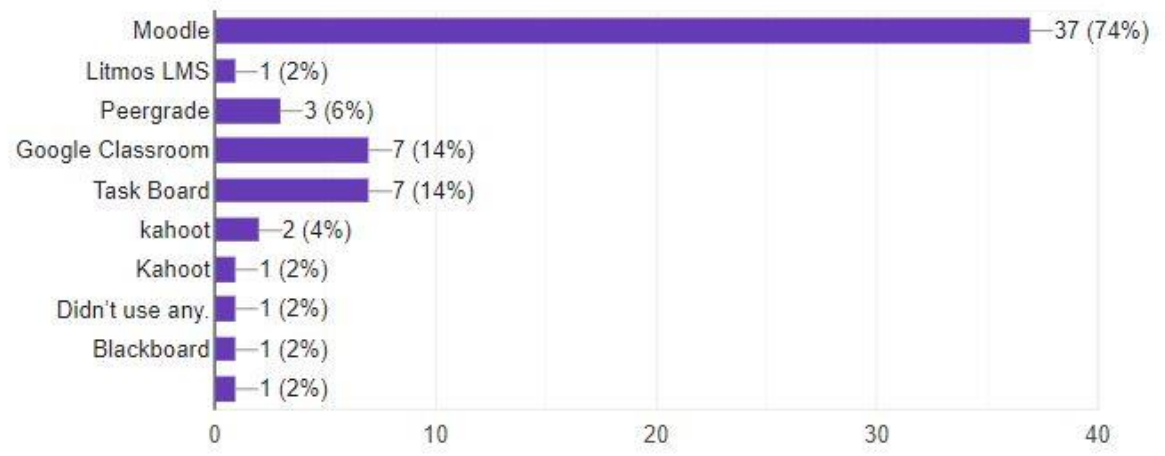

Fig 3.4: Analysis Question 4

The answers show that various e-learning tools are being used in educational institutes for various purposes, which also means that the students are comfortable with using various e-learning tools in their studies, and confirms that students do accept the use of e-learning tools in their classes.

Question 5 (analyzed by Fig. 3.5): Changes in the methods of teaching and learning have a positive outcome on the students.
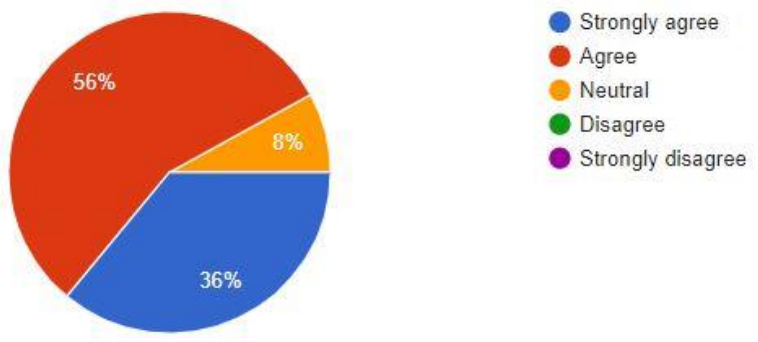

Fig 3.5: Analysis Question 5

The statement was addressed to the students to get their input on whether changing the methods of teaching in their current classes would affect their learning in a positive or a negative way. 50 out of 50 respondents answered this question, 28 answered Agree, 18 answered Strongly Agree, while the remaining 4 answered Neutral. Which shows that students do need changes in the current teaching and learning methods that are used in their classrooms. None of the respondents answered negatively which ensures that changing the teaching and learning methods that are used would have a positive impact on the students.

Question 6 (analyzed by Fig. 3.6): It is really important to look into the existing system of collaborative learning and update its Framework based on the current scenario of higher education.
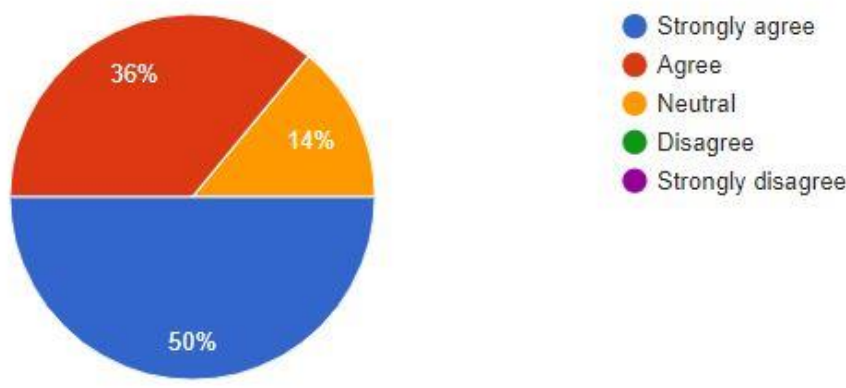

Fig 3.6: Analysis Question 6 
The statement was given to the respondents to assess the requirement of changing the current collaborative learning framework used by their teachers in their classes, and if changing the framework to fit the current state of the field of higher education is necessary for them. 50 out of 50 respondents answered this question. 25 of the answered Strongly Agree, while 18 answered Agree and 7 answered Neutral. Majority of the students or the respondents agreed that the current collaborative learning framework that is being used in their educational institutes do not fit the current state or scenario of the higher education. With that being said, the current collaborative learning framework needs to be revised and changed to better fit the scenario of the higher education.

\section{PROPOSED FRAMEWORK}

The Framework proposed consists of five main phases, each phase comes with sub tasks that are required in order to complete a phase and move forward in the framework as shown in Fig. 4.1.

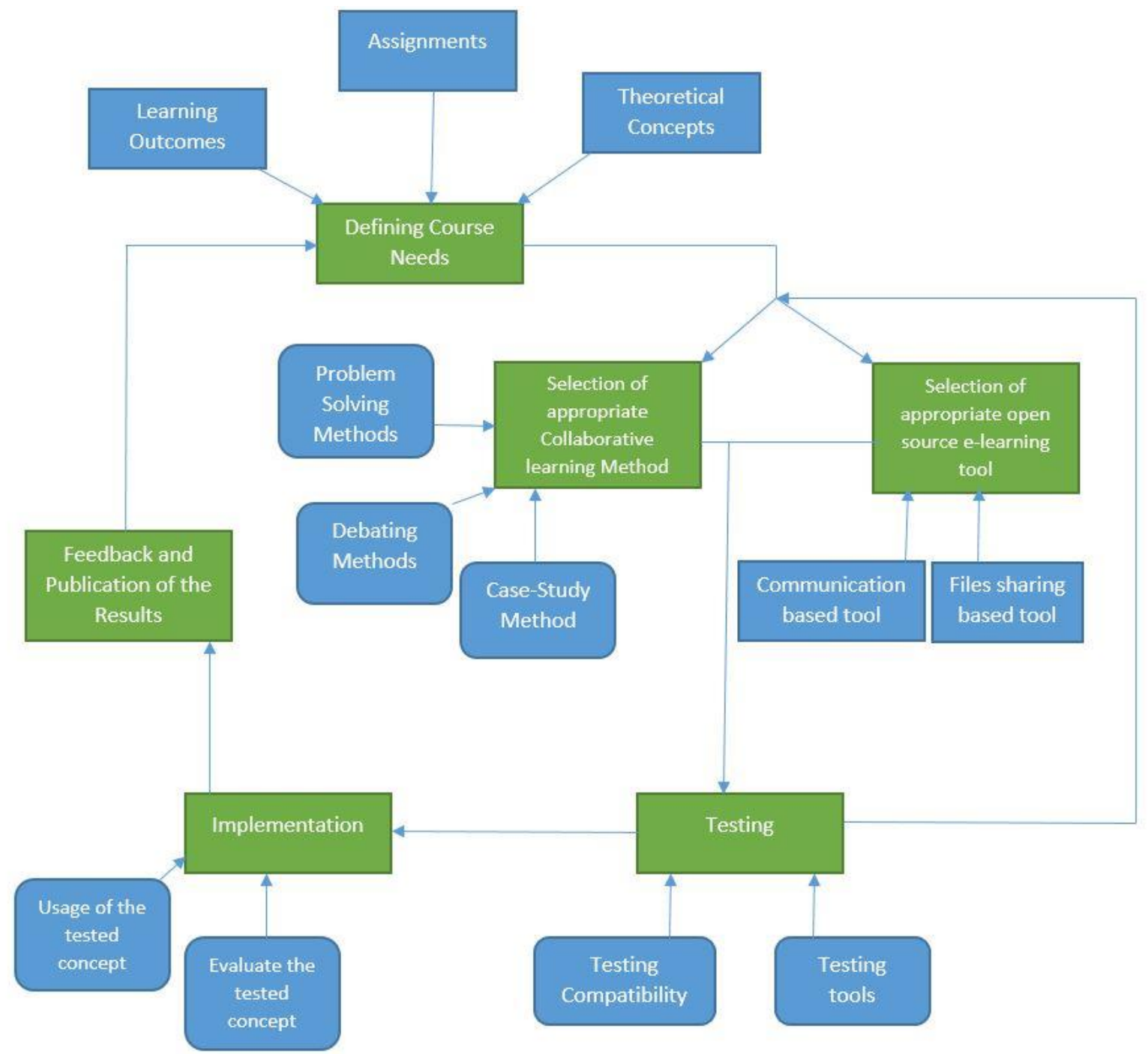

Fig 4.1: Proposed Framework

\subsection{Defining Course Needs}

The first phase consists of the teacher or lecturer defining what the course needs, and that takes action when the teacher or lecturer plans for the course. In this phase the teacher would have to check the learning outcomes, the assignments that would be given during the course as well as the theoretical concepts that will be taught within the course. That would give the teacher an idea on whether the course is compatible with the framework or not. 


\subsection{Selection of Appropriate Collaborative Learning Method}

After defining the course needs comes the selection of collaborative learning method because there are different methods that can be used in various situations from problem solving methods, to debating or discussion methods or case-study methods.

\subsection{Selection of Appropriate Open Source E-Learning Tool}

Selection of the tool is a critical phase because there are many open source e-learning tools. The tools are divided into two main categories which are the communication based tools that focus more on the communication between the students such as sharing ideas or discussions. And File sharing based tools that would work best with the case-study methods because it allows the students to share their work with their groups.

The e-tools are categories broadly into three: Freeware, Freemium and Free and Open Source. The freeware tools are completely free to use but cannot be customized. Some examples are NCH Video Pad Video Editor, a tool that can be used to edit video, Screen Recorder, etc. Freemium tools are those, which has limited features to use for free but in order to make full use of them, we need to buy the licence. Some online tools such as GoAnimatePro, using which we can create 2D animated demos for free is an example. On the other hand, there are many free and open source tools which can be downloaded for complete customization for educational need. Moodle (Learning Management System) is one of the best example. Apart from these H5P is another emerging free and open source online tool, by using which we can create many class activities, that is appropriate for the particular subject / topic.

\subsection{Testing}

In this phase, the selected tool and collaborative learning method are tested in order to check their compatibility with each other as well as with the course needs. Moreover, the tool selected is tested, learned and prepared for the classroom in order for the teacher to start using the tool once the course or class starts.

\subsection{Implementation}

The selected collaborative learning method and the selected open source e-learning tool are taken to the classroom on this phase. After the teacher applies the tested concept with the students, the teacher evaluates the tested concept based on how the students performed by using the concept, whether the learning outcomes are met, and if the combination used was accepted by the students.

\subsection{Feedback and Publication of the Results}

After the Implementation phase is done, the evaluation done by the teacher is taken, feedback is applied to it and the results are published so that other teachers can use the same combination of methods and tools in order to achieve the learning outcomes that were evaluated by the previous teacher. Hence, this phase goes back to defining course needs.

\section{RECOMMENDATIONS AND CONCLUSION}

The proposed framework provides a clear insight of collaborative learning environment coupled with free and open source tools. It can be easily customized since the tools are free and open source, when different necessity arises. There are many teachers with non-IT background for whom it becomes difficult to adapt such technologies and learn new tools. For them easy-to customize tools such as H5P could be very beneficial.

To meet the future demands of education paradigm shifting to Education 4.0 where innovative producing education is provided. To achieve this different new tools and technologies aid to assist not only to educators but to the faculties' as well. These technologies can be from capturing student's participation and engagement within the module not only inside the campus but outside the campus as well with the help of loT and ontology (Mahmood et al., 2019) (Sarker et al., 2019). Virtual Learning Environment can also be used in conjunction to the different blended learning environment's to cater different types of students (Hasan et al., 2019). Cloud based education can enrich the learning activities outside the campus, multimedia and social media can also be used as a collaborative tools (Hasan et al., 2019) (Bhat, Naidu \& Singh, 2018) (Naidu, Bhat \& Singh, 2019) (Ali \& Naidu, 2019). These can only be achieved by applying the Human Computer Interaction for better e-learning solution designs (Al Mahdi, Rao Naidu \& Kurian, 2019). In collaborative environment, students can be involved to make modifications in the existing models of teaching and learning and thus we can get inputs from every stakeholder in order to enhance teaching and learning experience. 


\section{REFERENCE LIST}

Al Mahdi, Z., Rao Naidu, V., \& Kurian, P. (2019). Analyzing the Role of Human Computer Interaction Principles for E-Learning Solution Design. Smart Technologies and Innovation for a Sustainable Future, 41-44. doi: 10.1007/978-3-030-01659-3_6

Ali, Q., \& Naidu, V. (2019). Using Social Media as a Collaborative Tool for Enhanced Learning in Higher Education. $6^{\text {th }}$ Academic International Conference on Multi-Disciplinary Studies and Humanities (pp. 85-92). Oxford: Oxford Conference Series.

Bhat, A., Naidu, V., \& Singh, B. (2018). Multimedia Cloud for Higher Education Establishments: A Reflection. Advances in Intelligent Systems And Computing, 691-698. doi: 10.1007/978-981-13-2285-3_81

Bhatia, S., \& Naidu, V. R. (2017). Flipped Teaching in Mathematics. International Conference on Education and New Learning Technologies. Barcelona, Spain: EDULEARN17.

Bhatti, A. H., Hasan, R., Farsi, A. A., \& Kazmi, S. I. (2017). Dynamic Technology Tool to Support Active Learning in Mathematics. 2017 International Symposium on Educational Technology (ISET). Hong Kong, China: IEEE.

Farsi, M. H., Udupi, P. K., \& Naidu, V. R. (2017). Interactive Education Application Development Using FOSS for Government School in Oman. Free and Open Source Software Conference , (pp. 71-75). Muscat, Oman.

GebreYohannes, H. M., Bhatti, A. H., \& Hasan, R. (2016). Impact of multimedia in Teaching Mathematics. International Journal of Mathematics Trends and Technology (IJMTT), 39(1).

Hasan, R, Palaniappan, S, Mahmood, S, Shah, B, Abbas, A, Sarker, K. (2019). Enhancing the Teaching and Learning Process Using Video Streaming Servers and Forecasting Techniques. Sustainability 11(7): 2049.

Hasan, R., Ghufran, M., Javed, S., Hammad-ul-Haq, Azeem, A., \& Jamil, D. (2019). SMART Virtual Dental Learning Environment. $20194^{\text {th }}$ MEC International Conference on Big Data And Smart City (ICBDSC). doi: 10.1109/icbdsc.2019.8645584

Hasan, R., \& Mahmood, S. (2012). Survey and evaluation of simulators suitable for teaching for computer architecture and organization Supporting undergraduate students at Sir Syed University of Engineering \& Technology. Proceedings of 2012 UKACC International Conference on Control (pp. 1043-1045). Cardiff, UK : IEEE.

Hasan, R., Ali, S. I., \& Hayat, M. (2015). Enhancing student's learning experience at middle east college by using blended learning. 2015 Science and Information Conference (SAI) (pp. 797-800). London, UK: IEEE.

Hayat, M., Hasan, R., Ali, S. I., \& Kaleem, M. (2017). Active learning and student engagement using Activity Based Learning. 2017 International Conference on Infocom Technologies and Unmanned Systems (Trends and Future Directions) (ICTUS). Dubai, United Arab Emirates: IEEE.

Kazmi, S. I., Hayat, M. S., Hasan, R., \& Dattana, V. (2017, October). Network simulation tool enhances learning and understanding of computer network protocol concepts in middle east college. Airo International Research Journal, 13.

Mahmood, S., Palaniappan, S., Hasan, R., Sarker, K., Abass, A., \& Rajegowda, P. (2019). Raspberry PI and role of IoT in Education. $20194^{\text {th }}$ MEC International Conference on Big Data And Smart City (ICBDSC). doi: 10.1109/icbdsc.2019.8645598

Naidu, V. R., Balushi, H. A., \& Bhatia, S. (2017). Effectiveness Of Free \& Open Source Tools To Enhance Game Based Learning Experience In School Education. International Conference on Education and New Learning Technologies. Barcelona, Spain: EDULEARN.

Naidu, V., Bhat, A., \& Singh, B. (2019). Cloud Concept for Implementing Multimedia Based Learning in Higher Education. Smart Technologies and Innovation for a Sustainable Future, 81-84. doi: 10.1007/978-3-030-01659-3_11

Naidu, V. R., Singh, B., Harrasi, R. A., \& Balushi, H. A. (2017). Technology Enhanced Learning Assisted By Free And Open Source Software. 4th International Conference on Education, Social Sciences and Humanities . Dubai, UAE: SOCIOINT. 
Naidu, V. R., Singh, B., Hasan, R., \& Hadrami, G. A. (2017). Learning Analytics for Smart Classrooms in Higher Education. International E-Journal of Advances in Education, 3(8), 440-446.

Raweehi, M. G., Ansari, W. A., Udupi, P. K., \& Naidu, V. R. (2017). Interactive E-Book Developement using FOSS. Free and Open Source Software Conference, (pp. 67-70). Muscat, Oman.

Sarker, K., Bin Deraman, A., Hasan, R., Mahmood, S., Abbas, A., \& Sohail, M. (2019). Kids' Smart Campus Ontology to Retrieve Interest. $20194^{\text {th }}$ MEC International Conference on Big Data And Smart City (ICBDSC). doi: 10.1109/icbdsc.2019.8645585

Siddiqui, O. A., Hasan, R., Mahmood, S., \& Khan, A. R. (2012). Simulators as a Teaching Aid for Computer Architecture and Organization. 2012 4th International Conference on Intelligent Human-Machine Systems and Cybernetics (pp. 110-113). Nanchang, Jiangxi, China: IEEE. 